\title{
DOUBLE SUBORDINATION PRESERVING PROPERTIES FOR GENERALIZED FRACTIONAL DIFFER-INTEGRAL OPERATOR
}

\author{
Jugal K. Prajapat And TeOdor BulboacĂ
}

Abstract. We obtain subordination and superordination preserving properties for the Saigo type generalized fractional differ-integral operator, defined for multivalent functions in the open unit disk. A differential sandwich-type theorem for these multivalent function, and some consequences are also presented.

Mathematics subject classification (2010): Primary: 30C80; Secondary: 30C45.

Keywords and phrases: Differential subordination and superordination, analytic functions, univalent functions, starlike functions, convex functions, generalized fractional differ-integral operator.

\section{REFERENCES}

[1] R. M. Ali, V. Ravichandran and N. SeEnivas Agan, Differential subordination and superordination of analytic functions defined by the multiplier transformation, Math. Inequal. Appl. 12 (2009), $123-139$.

[2] R. M. Ali, V. Ravichandran And N. Seenivasagan, Subordination and superordination of the Liu-Srivastava linear operator on meromorphic functions, Bull. Malays. Math. Sci. Soc. (2) 31, 2 (2008), 192-207.

[3] S. D. Bernardi, Convex and starlike univalent functions, Trans. Amer. Math. Soc. 135 (1969), 429446.

[4] T. Bulboac $\breve{A}$, Integral operators that preserve the subordination, Bull. Korean Math. Soc. 34 (1997), $627-636$.

[5] T. Bulboac $\breve{A}$, A class of superordination-preserving integral operators, Indag. Math. (N. S.) 13 (2002), 301-311.

[6] R. M. Goel And N. S. Sohi, A new criterion for p-valent functioons, Proc. Amer. Math. Soc. 78 (1980), 353-357.

[7] S. P. Goyal And J. K. PRAJAPat, A new classes of analytic p-valent functions with negative coefficents and fractional calculus operators, Tamsui Oxf. J. Math. Sci. 20, 2 (2004), 175-186.

[8] T. H. GronwalL, Some remarks on conformal representation, Ann. Math. 16 (1914/15), 72-76.

[9] I. B. Jung, Y. C. Kim And H. M. SRivastava, The Hardy space of analytic functions associated with certain one-parameter families of integral operators, J. Math. Anal. Appl. 176 (1993), 138-147.

[10] W. Kaplan, Close-to-convex schlicht functions, Michigan Math. J. 2 (1952), 169-185.

[11] R. J. LiberA, Some classes of regular univalent functions, Proc. Amer. Math. Soc. 16 (1965), 755758.

[12] S. S. Miller And P. T. Mocanu, Differential subordinations and univalent functions, Michigan Math. J. 28 (1981), 157-171.

[13] S. S. Miller, P. T. Mocanu And M. O. Reade, Subordination-preserving integral operators, Trans. Amer. Math. Soc. 283 (1984), 605-615.

[14] S. S. Miller And P. T. Mocanu, Univalent solutions of Briot-Bouquet differential equations, J. Differential Equations 56 (1985), 297-309.

[15] S. S. Miller and P. T. Mocanu, Differential Subordinations. Theory and Applications, New York and Basel, Marcel Dekker, 2000.

[16] S. S. Miller And P. T. Mocanu, Subordinants of differential superordinations, Complex Var. Theory Appl. 48 (2003), 815-826. 
[17] S. Owa, On the distortion theorems I, Kyungpook Math. J. 18 (1978), 53-59.

[18] S. OWA AND H. M. SRIVASTAVA, Some applications of the generalized Libera integral operator, Proc. Japan Acad. Ser. A Math. Sci. 62 (1986), 125-128.

[19] J. Patel AND A. K. Mishra, On certain subclasses of multivalent functions associated with an extended fractional differintegral operator, J. Math. Anal. Appl. 332 (2007), 109-122.

[20] Ch. Pommerenke, Univalent Functions, Vanderhoeck and Ruprecht, Göttingen, 1975.

[21] J. K. Prajapat, R. K. Raina And H. M. SRivastava, Some inclusion properties for certain subclasses of strongly starlike and strongly convex functions involving a family of fractional integral operators, Integral Transforms Spec. Funct. 18, 9 (2007), 639-651.

[22] J. K. PRAJAPAT, Inclusion properties for certain classes analytic functions involving a family of fractional integral operator, Fract. Calc. Appl. Anal. 11 (2008), 27-34.

[23] J. K. PRAJAPAT AND R. K. Raina, New sufficient conditions for starlikeness of analytic functions involving a fractional differintegral operators, Demonstratio Math. 43 (2010), 805-813.

[24] J. K. PRAJAPAT AND M. K. Aouf, Majorization problem for certain class of p-valently analytic function defined by generalized fractional differintegral operator, Comput. Math. Appl. 63 (2012), $42-47$.

[25] H. M. SRivastava ANd S. Owa (Eds.), Univalent Functions, Fractional Calculus, and Their Applications, Halsted Press (Chichester, Ellis Horwood Limited) (New York, Chichester, Brisbane and Toronto), John Wiley and Sons, 1989.

[26] H. M. Srivastava And S. Owa, Current Topics in Analytic Function Theory, Singapore, New Jersey, London and Hong Kong, World Scientific Publishing Company, 1992.

[27] H. M. SRivastaVA, M. SAIGO AND S. OWA, A class of distortion theorems involving certain operators of fractional calculus, J. Math. Anal. Appl. 131 (1988), 412-420.

[28] S. Supramaniam, R. M. Ali, S. K. Lee and V. Ravichandran, Convolution and differential subordination for multivalent functions, Bull. Malays. Math. Sci. Soc. (2) 32, 3 (2009), 351-360.

[29] Z.-G. WANG, R.-G. XIANG AND M. DARUS, A family of integral operators preserving subordination and superordination, Bull. Malays. Math. Sci. Soc. (2) 33, 1 (2010), 121-131.

[30] E. T. Whittaker and G. N. Watson, A Course of Modern Analysis: An Introduction to the General Theory of Infinite Processes and of Analytic Functions; With an Account of the Principal Transcendental Functions, Fourth Edition, Cambridge University Press, Cambridge, 1927. 